\title{
Identifikasi Perubahan Tutupan Lahan Pascaletusan Gunungapi Sinabung Tahun 2010 Berbasis Citra Landsat 5 TM
}

\author{
THONAS INDRA MARYANTO, PUSAIN SOLIDER ZEGA
}

\author{
Jurusan Teknik Geodesi \\ FTSP - Institut Teknologi Nasional, Bandung \\ Email: thonas@itenas.ac.id
}

\begin{abstract}
ABSTRAK
Indonesia merupakan negara yang rawan terhadap berbagai jenis bencana geologi. Salah satu bencana geologi yang sering terjadi adalah erupsi gunungapi. Gunung Sinabung merupakan gunungapi yang terletak di Kabupaten Karo, Sumatera Utara. Gunungapi ini telah mengalami letusan pada tahun 2010, menyemburkan abu vulkanik hingga menyebabkan kerusakan terhadap tutupan lahan yang berada di area letusan tersebut. Tujuan penelitian ini adalah untuk mengidentifikasi perubahan tutupan lahan di Kecamatan Payung, Naman Teran, Tiganderket, Merdeka, dan Simpang Empat. Data yang digunakan adalah Citra Landsat 5 TM tahun 2009 dan 2011. Identifikasi tutupan lahan dilakukan dengan metode Supervised Maximum Likelihood Classification. Hasil analisis menunjukkan adanya perubahan tutupan lahan pada tahun 2009-2011, yaitu hutan berkurang 1,6\%, bangunan bertambah 0,2\%, kebun bertambah 9,0\%, semak berkurang 6,8\%, dan sawah berkurang 0,2\%.
\end{abstract}

Kata kunci: perubahan tutupan lahan, supervised maximum likelihood classification, citra Landsat 5 TM

\begin{abstract}
Indonesia is a vulnerable country to various types of geological disasters. One of the frequent geological disasters is volcanic eruption. Mount Sinabung is a volcano located in Karo Regency, North Sumatera. This volcano has erupted in 2010, spewing volcanic ash which caused damage to land cover in the eruption area. The purpose of this study is to identify land cover changes in Payung, Naman Teran, Tiganderket, Merdeka, and Simpang Empat Districts. The data used are Landsat 5 TM imagery in 2009 and 2011. Identification of land cover is carried out using the Supervised Maximum Likelihood Classification method. The results of the analysis show that there was a change in land cover in 2009-2011, ie forest decreased by 1.6\%, building increased by $0.2 \%$, farm increased by $9.0 \%$, bush decreased by $6.8 \%$, and rice field decreased by $0.2 \%$.
\end{abstract}

Keywords: land cover change, supervised maximum likelihood classification, Landsat 5 TM imagery 


\section{PENDAHULUAN}

Gugusan kepulauan nusantara terletak pada jalur "Ring of Fire" dunia. Jalur tersebut merupakan sumber gempa bumi, tumbuh dan berkembangnya gunungapi. Dengan demikian, keadaan tersebut merupakan berkah sekaligus ancaman bahaya yang sewaktu-waktu tanpa dapat diprediksi dengan tepat dapat berubah menjadi bencana yang mematikan (Tjandra, 2015). Dalam Peraturan Kepala Badan Nasional Penanggulangan Bencana Nomor 2 Tahun 2012, dijelaskan bahwa secara geologis, Indonesia terletak pada 3 (tiga) lempeng, yaitu Lempeng Eurasia, Indo-Australia, dan Pasifik yang membuat Indonesia kaya dengan cadangan mineral sekaligus mempunyai dinamika geologis yang sangat dinamis yang mengakibatkan potensi bencana gempa bumi, tsunami, dan gerakan tanah/longsor. Selain itu, Indonesia mempunyai banyak gunungapi aktif yang sewaktu-waktu dapat meletus. Seperti halnya Gunungapi Sinabung.

Gunungapi Sinabung merupakan gunungapi yang terletak di Dataran Tinggi Karo, Kabupaten Karo, Provinsi Sumatera Utara. Ketinggian gunungapi ini sekitar 2.460 mdpl. Gunungapi Sinabung tercatat tidak pernah meletus sejak tahun 1600-an, tetapi mendadak aktif kembali pada Agustus 2010 dan masih berlangsung hingga kini (Pandia dkk., 2016). Menurut sejarahnya, sebelum tahun 1600 di Gunung Sinabung terjadi erupsi dengan muntahan batuan piroklastik (awan panas, batu pijar, abu vulkanik) dan lahar dingin. Selanjutnya selama 400 tahun berikutnya tidak ada erupsi yang membahayakan, hanya tahun 1975-1976 terjadi beberapa kali erupsi freatik kecil. Tanggal 29 Agustus 2010 terjadilah erupsi besar di Gunung Sinabung (BNPB, 2013a). Pada tahun 2010, letusan terbesar terjadi pada 7 September dengan lontaran debu vulkanik hinga 5.000 meter ke udara. Suara letusan pun terdengar hingga jarak $8 \mathrm{~km}$. Mengantisipasi bahaya erupsi/letusan saat itu, sekitar 12.000 warga dievakuasi ke jambor-jambor di wilayah Kaban Jahe. Lontaran debu vulkanik cenderung meluncur dari arah barat daya menuju timur laut sehingga sebagian Kota Medan terselimuti debu Gunungapi Sinabung (BNPB, 2013b).

Letusan Gunungapi Sinabung berpotensi bahaya terhadap aktivitas masyarakat di sekitar lereng. Menurut BNPB (2017), bahaya dari letusan gunungapi dapat berupa awan panas, Iontaran material (pijar), hujan abu lebat, lava, gas racun, tsunami, dan banjir lahar. Bahaya letusan gunungapi dibedakan menjadi 2 (dua), yaitu bahaya primer dan bahaya sekunder. Bahaya primer adalah bahaya yang langsung menimpa penduduk ketika letusan berlangsung, misalnya awan panas, udara panas sebagai akibat samping awan panas, dan lontaran material berukuran blok (bom) hingga kerikil. Sedangkan bahaya sekunder terjadi secara tidak langsung dan umumnya berlangsung setelah letusan-letusan terjadi, seperti lahar dingin yang dapat menyebabkan kerusakan lahan dan pemukiman (Rahayu dkk., 2014). Bahaya letusan gunungapi memiliki resiko yang sangat tinggi, jika terjadi di wilayah yang padat penduduk dan banyak infrastruktur yang penting di daerah tersebut (Sofan dan Yulianto, 2014).

Letusan Gunungapi Sinabung memberikan dampak yang sangat terasa bagi masyarakat yang tinggal di sekitar lereng, terutama di daerah yang mempunyai radius kurang lebih $7 \mathrm{~km}$ dari puncak Gunungapi Sinabung. PVMBG telah memetakan potensi bahaya letusan Gunungapi Sinabung yang mungkin terjadi dalam bentuk kawasan rawan bencana Gunungapi Sinabung. Berdasarkan Peta Kawasan Rawan Bencana Gunungapi Sinabung (PVMBG, 2014), daerahdaerah yang berada dalam kawasan rawan bencana meliputi 5 (lima) kecamatan, yaitu Kecamatan Payung, Naman Teran, Tiganderket, Merdeka, dan Simpang Empat. Banyaknya material letusan Gunungapi Sinabung telah memberikan dampak pada kerusakan lahan di sekitar lereng gunungapi tersebut. Oleh karena itu, penelitian ini akan mengkaji perubahan 
tutupan lahan yang terjadi pascaletusan Gunungapi Sinabung pada tahun 2010 di 5 kecamatan tersebut. Untuk mengetahui perubahan tutupan lahan yang terjadi, maka digunakan Citra Satelit Landsat 5 TM tahun 2009 dan 2011, citra satelit sebelum dan setelah terjadi letusan Gunungapi Sinabung. Khomarudin dkk. (2014) menyebutkan bahwa Citra Satelit Landsat merupakan produk teknologi pengindraan jauh yang dapat digunakan untuk analisis berbagai keperluan, salah satunya adalah deteksi perubahan lahan yang diakibatkan oleh bencana alam. Adapun metode yang digunakan untuk identifikasi tutupan lahan pada masing-masing periode adalah Supervised Maximum Likelihood Classification.

\section{METODOLOGI}

Data yang digunakan dalam penelitian ini merupakan kompilasi data yang diperoleh dari Badan Informasi Geospasial (BIG) dan United States Geological Survey (USGS), secara detail tersaji pada Tabel 1.

Tabel 1. Data Penelitian

\begin{tabular}{clll}
\hline No & \multicolumn{1}{c}{ Data } & \multicolumn{1}{c}{ Akusisi Tahun } & \multicolumn{1}{c}{ Sumber } \\
\hline 1 & Citra Landsat 5 TM & 30 Juli 2009 & https://earthexplorer.usgs.gov \\
2 & Citra Landsat 5 TM & 04 Desember 2011 & https://earthexplorer.usgs.gov \\
3 & Peta RBI 1:50.000 & 2017 & Badan Informasi Geospasial \\
\hline
\end{tabular}

Metodologi identifikasi perubahan tutupan lahan pascaletusan Gunungapi Sinabung dapat dilihat pada Gambar 1.

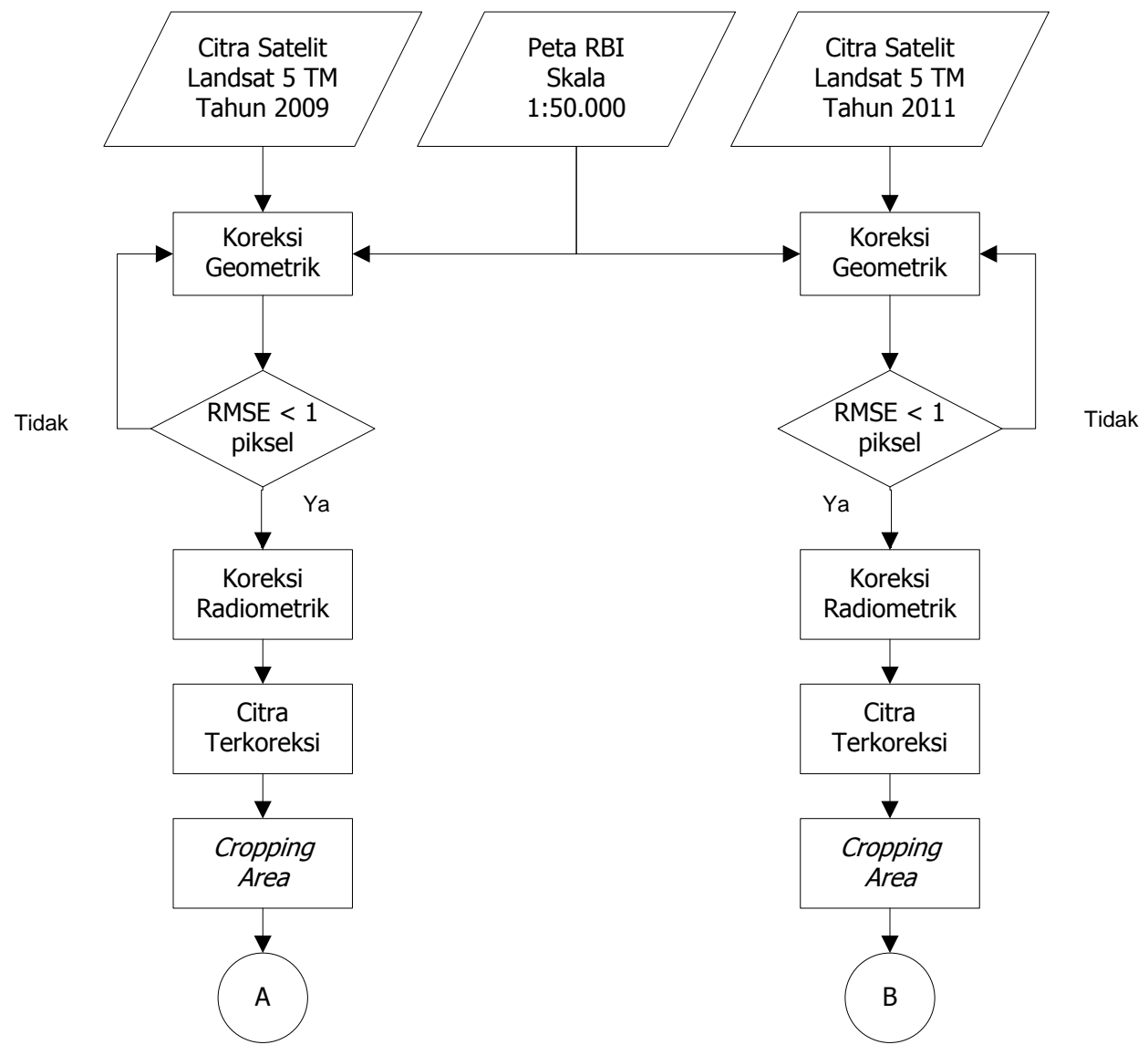

Gambar 1. Metodologi Penelitian

Reka Geomatika - 64 


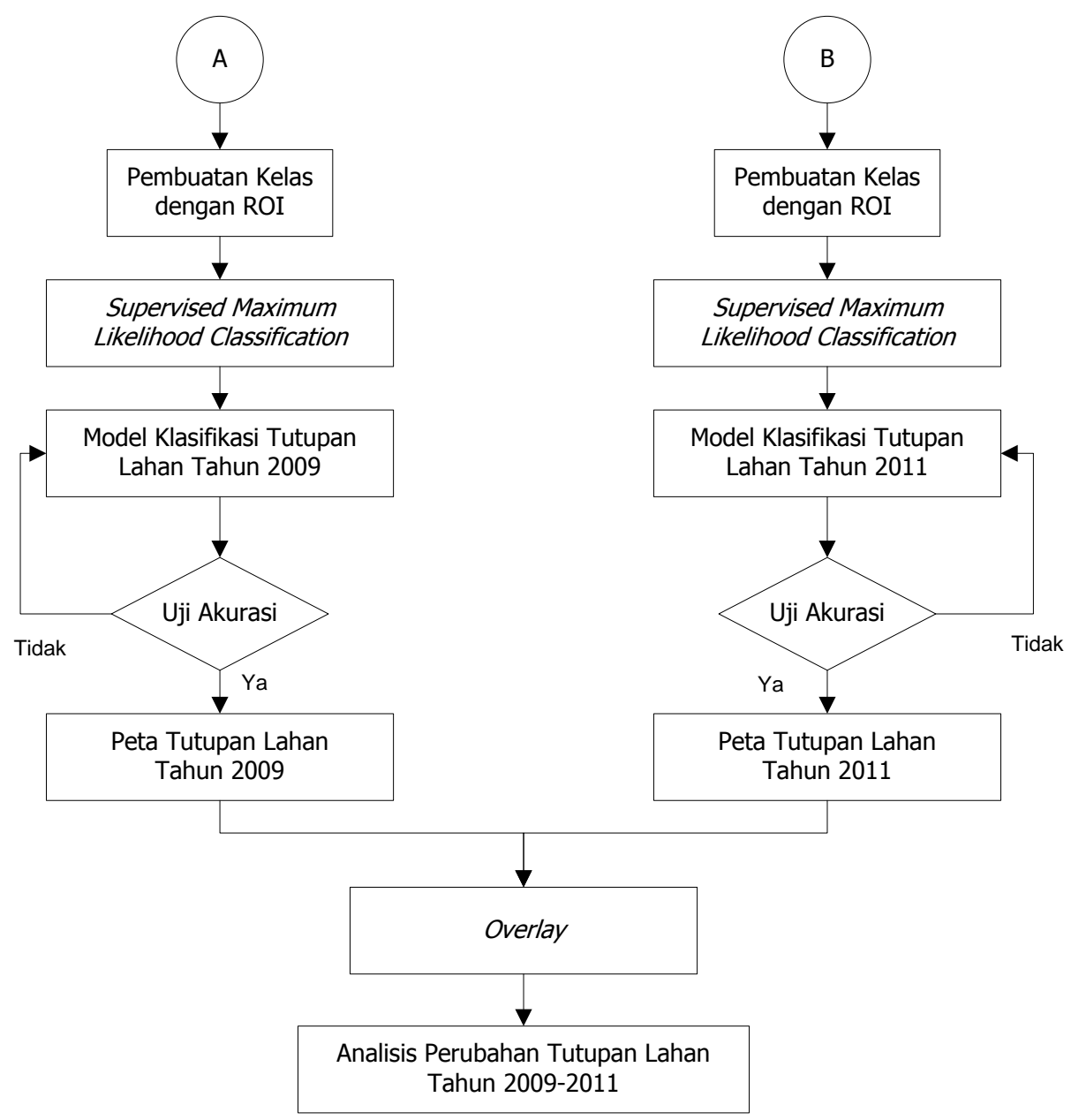

\section{Gambar 1. Metodologi Penelitian (lanjutan)}

Secara garis besar, proses dalam penelitian terbagi dalam 4 (empat) tahapan, yaitu prapengolahan citra, cropping citra, klasifikasi, dan uji akurasi.

a. Tahap pertama merupakan pra pengolahan citra yang mencakup koreksi geometrik dan koreksi radiometrik. Koreksi geometrik bertujuan untuk membenarkan dan memberikan posisi pada piksel citra sesuai dengan lokasi sebenarnya di permukaan bumi (Danoedoro, 2012). Koreksi geometrik yang dilakukan adalah image to map, yaitu antara Citra Landsat dengan Peta Rupa Bumi Indonesia skala 1:50.000. Setelah citra terkoreksi geometrik kemudian dilakukan koreksi radiometrik yang bertujuan untuk memperbaiki kualitas visual citra dan memperbaiki nilai-nilai piksel yang tidak sesuai dengan nilai spektral sebenarnya yang disebabkan kesalahan sistem optik, ganggguan atmosferik dan pengaruh sudut elevasi matahari (Purwadhi, 2001).

b. Tahap kedua adalah pemotongan (cropping) citra. Tujuannya untuk mendapatkan daerah penelitian agar lebih memudahkan dalam melakukan pengolahan data, lebih fokus dan optimal.

c. Tahap ketiga adalah klasifikasi. Proses klasifikasi untuk citra dilakukan dengan membuat sampel untuk sebaran wilayah yang diteliti sehingga sebaran tersebut dapat diidentifikasi. Pada pembuatan sampel ini dilakukan pembuatan kelas ROI (Region of Interest), dimana kelas yang dibuat dari sampel tersebut terdiri dari hutan, bangunan, kebun, sawah, semak dan tutupan awan. 
d. Tahap keempat adalah uji akurasi.

Uji akurasi digunakan untuk mengetahui tingkat ketepatan hasil klasifikasi yang telah dibuat berdasarkan confusion matrix. Confusion matrix merupakan matriks bujur sangkar yang memuat sejumlah piksel yang telah diklasifikasi. Uji akurasi ini dinilai dari user's accuracy, producer's accuracy, overall accuracy, dan kappa coefficient. Keempat nilai uji akurasi tersebut diformulasikan sebagai berikut (Sarkar, 2018):

$$
\begin{aligned}
& \text { User's Accuracy }=\frac{\text { Jumlah piksel yang diklasifikasikan dengan benar di setiap kategori }}{\text { Jumlah seluruh piksel yang terklasifikasi dalam kategori tersebut (Jumlah baris) }} \times 10 \mathrm{C} \\
& \text { Producer's Accuracy }=\frac{\text { Jumlah piksel yang diklasifikasikan dengan benar di setiap kategori }}{\text { Jumlah seluruh piksel yang terklasifikasi dalam kategori tersebut (Jumlah kolom) }} \times 10 \mathrm{C} \\
& \text { Overall Accuracy }=\frac{\text { Jumlah seluruh piksel yang diklasifikasikan dengan benar (Jumlah diagonal) }}{\text { Jumlah seluruh piksel referensi (Jumlah sampel) }} \times 10 \mathrm{C} \\
& \text { Kappa Coefficient }=\frac{\text { (Jumlah sampel } x \text { Jumlah sampel yang benar) }-\sum(J u m l a h \text { kolom } x \text { Jumlah baris })}{\text { Jumlah sampel } \left.{ }^{2}-\sum \text { Jumlah kolom } x \text { Jumlah baris }\right)}
\end{aligned}
$$

\section{HASIL DAN ANALISIS}

\subsection{Hasil Uji Akurasi}

\begin{tabular}{|c|c|c|c|c|c|c|c|c|c|}
\hline & & \multicolumn{8}{|c|}{ Google Earth } \\
\hline & $\begin{array}{c}\text { Klasifikasi } \\
\text { Tutupan Lahan }\end{array}$ & Hutan & Sawah & Semak & Permukiman & Kebun & $\begin{array}{c}\text { Tutupan } \\
\text { Awan }\end{array}$ & Total & $\begin{array}{c}\text { Users Accuracy } \\
(\%)\end{array}$ \\
\hline \multirow{7}{*}{$\stackrel{0}{\frac{0}{*}}$} & Hutan & 671 & 0 & 14 & 0 & 0 & 0 & 685 & 97,96 \\
\hline & Sawah & 0 & 209 & 10 & 22 & 105 & 9 & 355 & 58,87 \\
\hline & Semak & 37 & 71 & 99 & 5 & 201 & 0 & 413 & 23,97 \\
\hline & Permukiman & 0 & 2 & 1 & 545 & 6 & 14 & 568 & 95,95 \\
\hline & Kebun & 8 & 42 & 11 & 27 & 162 & 24 & 274 & 59,12 \\
\hline & Tutupan Awan & 4 & 0 & 0 & 4 & 10 & 385 & 403 & 95,53 \\
\hline & \begin{tabular}{|l|} 
Total \\
\end{tabular} & 720 & 324 & 135 & 603 & 484 & 432 & 2698 & \\
\hline \multicolumn{2}{|c|}{ Producer Accuracy (\%) } & 93,19 & 64,51 & 73,33 & 90,38 & 33,47 & 89,12 & & \\
\hline \multicolumn{2}{|c|}{ Overall Accuracy (\%) } & \multicolumn{8}{|c|}{76,76} \\
\hline \multicolumn{2}{|c|}{ Kappa Coefficient } & \multicolumn{8}{|c|}{0,72} \\
\hline
\end{tabular}

Hasil uji akurasi klasifikasi tutupan lahan tahun 2009 dan 2011 menggunakan confusion matrix disajikan pada Tabel 2 dan 3.

\begin{tabular}{|c|c|c|c|c|c|c|c|c|c|}
\hline & & \multicolumn{8}{|c|}{ Google Earth } \\
\hline & $\begin{array}{c}\text { Klasifikasi Tutupan } \\
\text { Lahan }\end{array}$ & Hutan & Sawah & Semak & Permukiman & Kebun & $\begin{array}{l}\text { Tutupan } \\
\text { Awan }\end{array}$ & Total & $\begin{array}{c}\text { Users Accuracy } \\
\text { (\%) }\end{array}$ \\
\hline \multirow{7}{*}{ 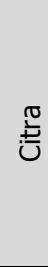 } & Hutan & 473 & 0 & 18 & 0 & 6 & 0 & 497 & 95,17 \\
\hline & Sawah & 3 & 121 & 15 & 3 & 65 & 0 & 207 & 58,45 \\
\hline & Semak & 11 & 21 & 81 & 6 & 101 & 1 & 221 & 36,65 \\
\hline & Permukiman & 0 & 0 & 7 & 255 & 7 & 0 & 269 & 94,80 \\
\hline & Kebun & 7 & 65 & 41 & 6 & 154 & 0 & 273 & 56,41 \\
\hline & Tutupan Awan & 0 & 0 & 0 & 0 & 0 & 125 & 125 & 100,00 \\
\hline & Total & 494 & 207 & 162 & 270 & 333 & 126 & 1592 & \\
\hline \multicolumn{2}{|c|}{ Producer Accuracy (\%) } & 95,75 & 58,45 & 50,00 & 94,44 & 46,25 & 99,21 & & \\
\hline \multicolumn{2}{|c|}{ Overall Accuracy (\%) } & \multicolumn{8}{|c|}{75,94} \\
\hline \multicolumn{2}{|r|}{ Kappa Coefficient } & \multicolumn{8}{|c|}{0,70} \\
\hline
\end{tabular}

Tabel 2. Hasil Uji Akurasi Klasifikasi Tutupan Lahan Tahun 2009

Tabel 3. Hasil Uji Akurasi Klasifikasi Tutupan Lahan Tahun 2011 
Berdasarkan Tabel 2 dan 3 dapat diketahui bahwa nilai overall accuracy pada klasifikasi tutupan lahan tahun 2009 adalah sebesar 76,76\% dan tahun 2011 adalah 75,94\%. Sedangkan nilai kappa coefficient pada klasifikasi tutupan lahan 2009 adalah 0,72 dan tahun 2011 adalah 0,70. USGS (2016) menyatakan bahwa citra hasil pengolahan memiliki akurasi baik dimana syarat minimum overral accuracy adalah $80 \%$ dan nilai kappa coefficient 0,80 . Mengacu pada aturan tersebut, maka hasil uji akurasi pada penelitian ini dinyatakan sudah cukup baik walaupun overall accuracy tidak mencapai $80 \%$. Hal ini disebabkan karena kompleksnya interaksi yang terjadi antar struktur spasial suatu bentang alam, resolusi citra, algoritma pengolahan, dan prosedur klasifikasi yang digunakan, seperti yang dijelaskan oleh Congalton dan Green (2008). Selain itu, faktor penyebab yang lain adalah perekaman citra landsat tahun 2009 dalam kondisi kurang maksimal (terlihat dari distorsi berupa garis lurus yang ikut terklasifikasi dan tutupan awan (cloud cover) yang cukup luas sebesar 686 ha dan tahun 2011 sebesar 470 ha.

Nilai uji akurasi yang dianjurkan untuk digunakan adalah kappa coefficient karena akurasi kappa coefficient menggunakan semua elemen dalam matriks. Berdasarkan nilai uji akurasi pada klasifikasi tutupan lahan 2009 dan 2011, keduanya memberikan nilai akurasi di bawah syarat minimum yang ditetapkan oleh USGS. Jika ditinjau berdasarkan tingkatan kriteria kappa coefficient oleh Rwanga dan Ndambuki (2017), nilai kappa coefficient dalam penelitian ini tergolong dalam tingkatan substansial, satu tingkat di bawah mendekati sempurna (almost perfect).

\subsection{Hasil Klasifikasi Tutupan Lahan}

Hasil penelitian ini berupa peta tutupan lahan tahun 2009 dan 2011. Visualisasi tutupan lahannya dapat dilihat pada Gambar 2 dan 3.

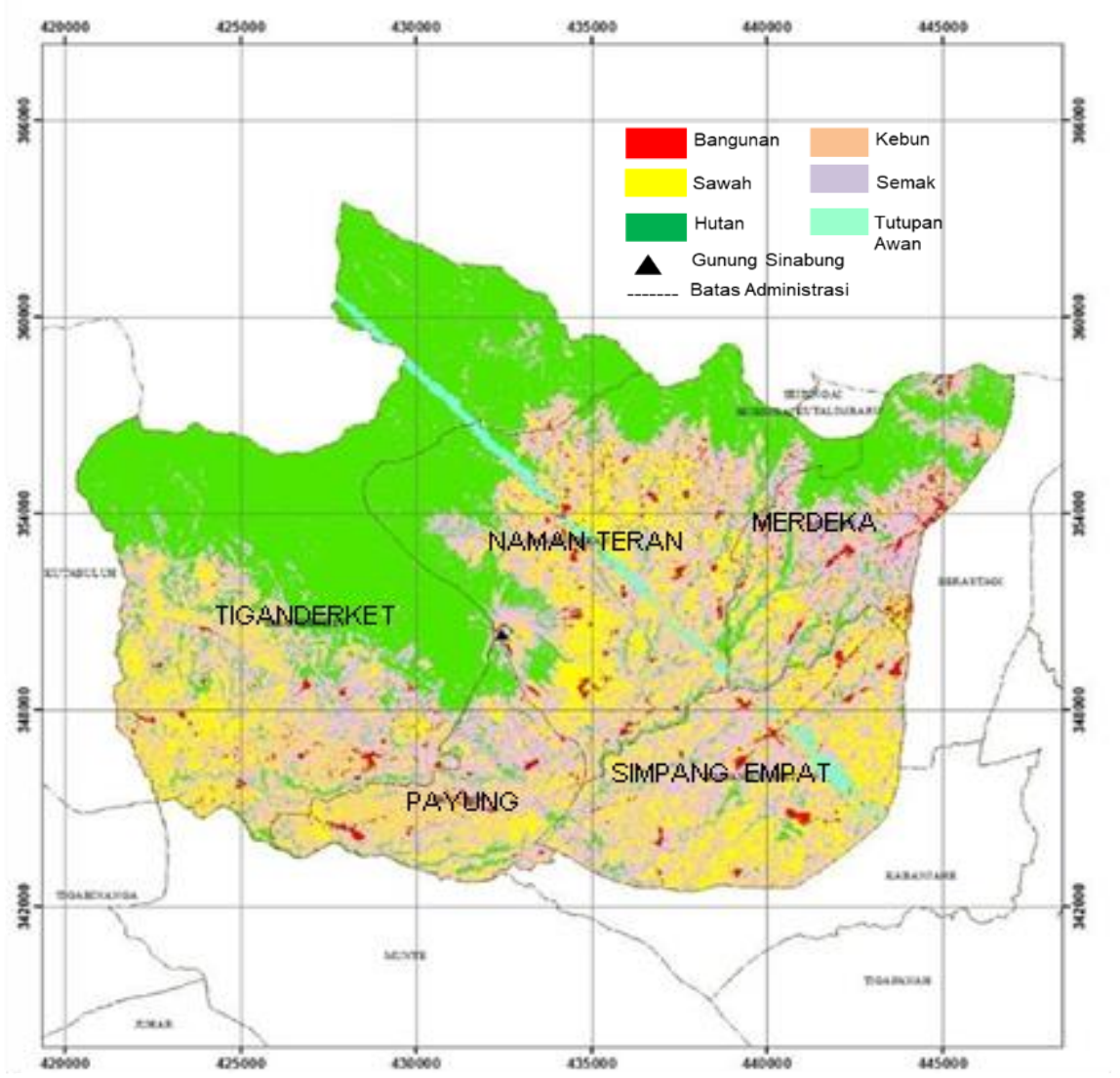

Gambar 2. Visualisasi Tutupan Lahan Tahun 2009

Reka Geomatika - 67 


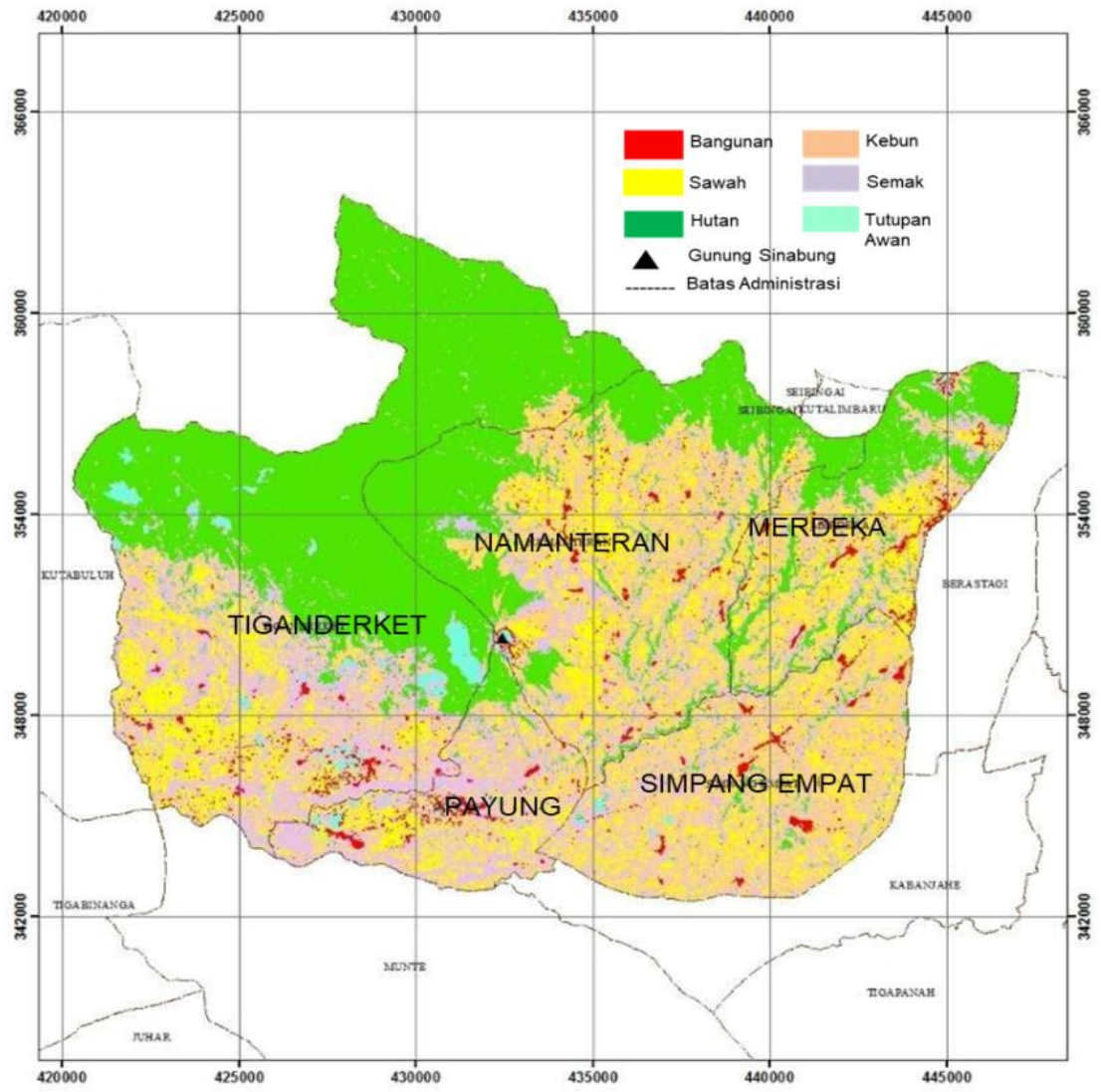

Gambar 3. Visualisasi Tutupan Lahan Tahun 2011

Berdasarkan hasil klasifikasi tutupan lahan tahun 2009 dan 2011 (seperti yang divisualisasikan pada Gambar 2 dan 3), selanjutnya dapat dihitung luas tutupan lahan masing-masing periode dan luas perubahan tutupan lahan yang terjadi di wilayah sekitar Gunungapi Sinabung (Kecamatan Payung, Naman Teran, Tiganderket, Merdeka, dan Simpang Empat), seperti yang dijelaskan pada Tabel 2.

Tabel 2. Perubahan Luas Tutupan Lahan di Wilayah Sekitar Gunungapi Sinabung Tahun 2009-2011

\begin{tabular}{|c|c|c|c|c|c|c|c|}
\hline \multirow[t]{2}{*}{ No } & \multirow{2}{*}{$\begin{array}{l}\text { Jenis Tutupan } \\
\text { Lahan }\end{array}$} & \multicolumn{2}{|c|}{ Luas Lahan (Ha) } & \multicolumn{2}{|c|}{$\begin{array}{c}\text { Persentase Luas } \\
\text { Lahan (\%) }\end{array}$} & \multicolumn{2}{|c|}{$\begin{array}{c}\text { Perubahan } \\
\text { Tutupan Lahan }\end{array}$} \\
\hline & & 2009 & 2011 & 2009 & 2011 & Luas $(\mathrm{Ha})$ & Persentase (\%) \\
\hline 1 & Hutan & 12.863 & 12.285 & 37,1 & 35,5 & -578 & $-1,6$ \\
\hline 2 & Bangunan & 698 & 765 & 2,0 & 2,2 & 67 & 0,2 \\
\hline 3 & Kebun & 4.526 & 7.669 & 13,1 & 22,1 & 3.143 & 9,0 \\
\hline 4 & Semak & 10.045 & 7.677 & 29,0 & 22,2 & -2.368 & $-6,8$ \\
\hline 5 & Sawah & 5.804 & 5.756 & 16,8 & 16,6 & -48 & $-0,2$ \\
\hline 6 & Tutupan Awan & 686 & 470 & 2,0 & 1,4 & -216 & $-0,6$ \\
\hline & Total & 34.622 & 34.622 & 100,0 & 100,0 & & \\
\hline
\end{tabular}

Secara detail, contoh perubahan tutupan lahan 2009-2011 dapat dilihat pada Gambar 4 s.d. Gambar 7, pada gambar-gambar tersebut perubahan tutupan lahan direpresentasikan dengan perubahan warna piksel hasil dari klasifikasi. 


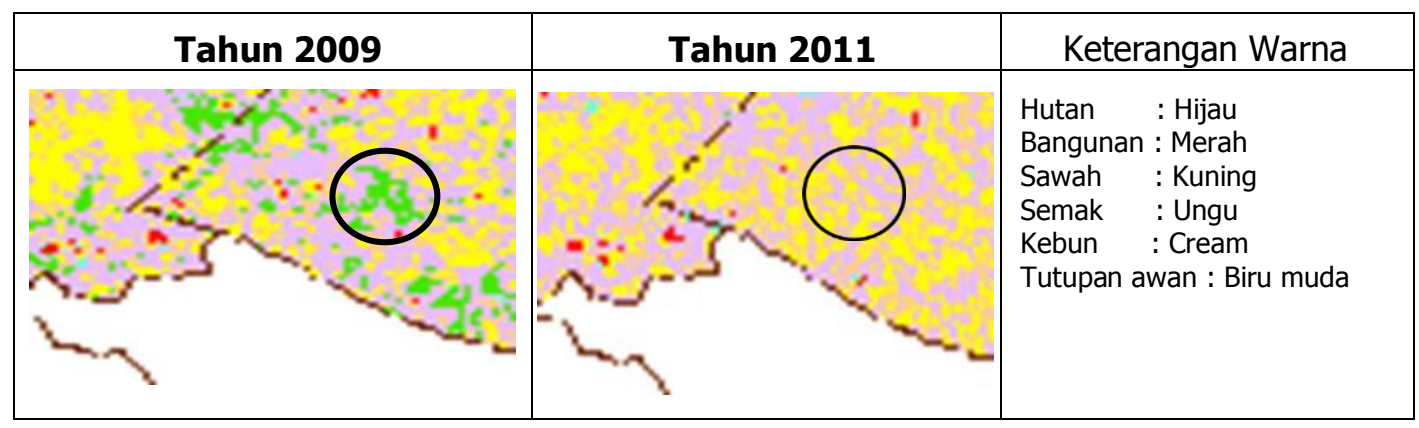

Gambar 4. Contoh Perubahan Tutupan Lahan Hutan Menjadi Sawah dan Semak

Gambar 4 menunjukkan contoh perubahan tutupan lahan hutan menjadi sawah di Kecamatan Simpang Empat, tutupan lahan hutan yang direpresentasikan dengan piksel warna hijau pada tahun 2009, pada tahun 2011 mengalami pengurangan, berubah menjadi sawah (yang direprentasikan dengan piksel warna kuning) dan semak (yang direpresentasikan dengan piksel warna ungu).

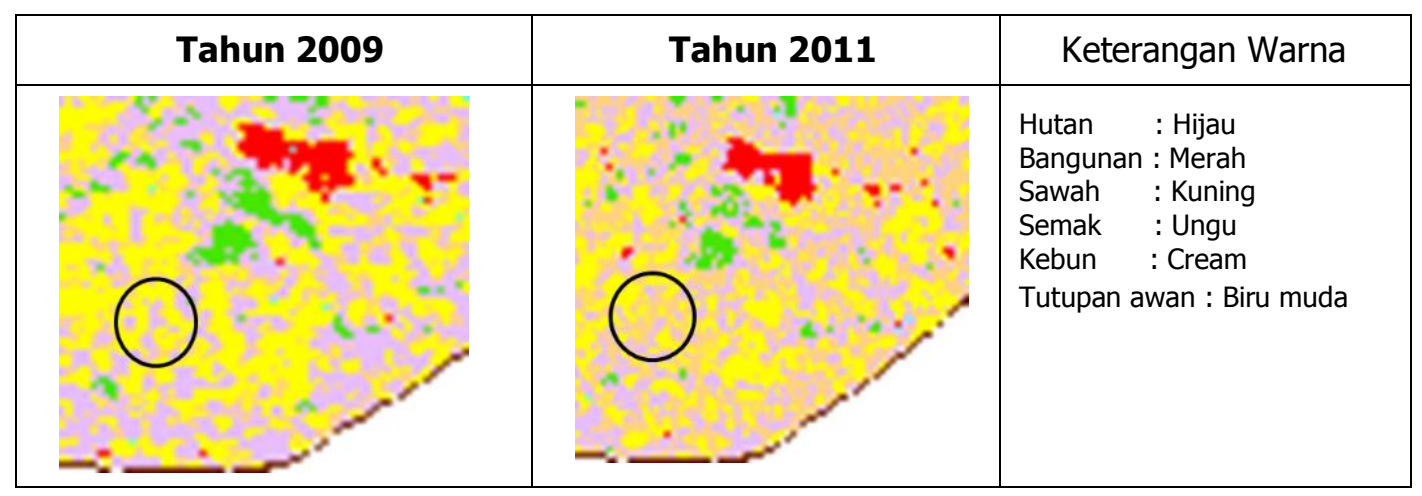

Gambar 5. Contoh Perubahan Tutupan Lahan Sawah Menjadi Kebun

Gambar 5 menunjukkan contoh perubahan tutupan lahan dari sawah menjadi kebun di Kecamatan Simpang Empat. Tutupan lahan sawah yang direpresentasikan dengan piksel warna kuning pada tahun 2009, pada tahun 2011 mengalami pengurangan, berubah menjadi tutupan lahan berupa kebun yang direpresentasikan dengan piksel warna cream.

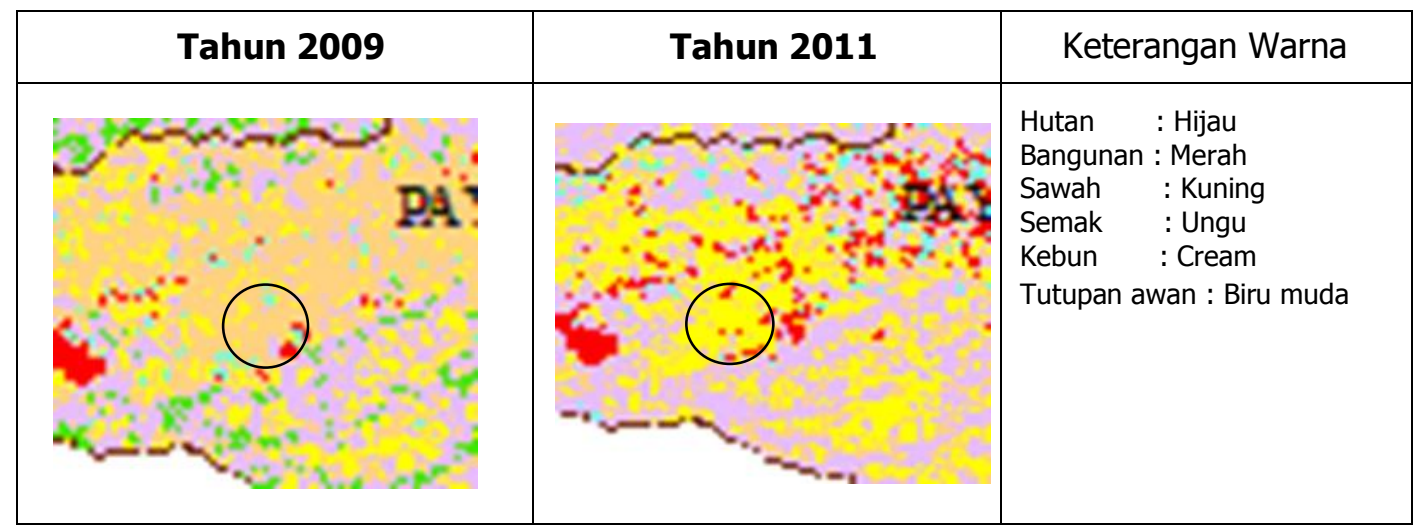

Gambar 6. Contoh Perubahan Tutupan Lahan Kebun Menjadi Sawah dan Bangunan

Gambar 6 menunjukkan contoh perubahan tutupan lahan berupa kebun menjadi sawah dan bangunan di Kecamatan Payung. Tutupan lahan kebun yang direpresentasikan dengan piksel warna cream pada tahun 2009, pada tahun 2011 mengalami pengurangan, berubah menjadi 
tutupan lahan berupa sawah dan bangunan yang direpresentasikan dengan piksel warna kuning dan merah.

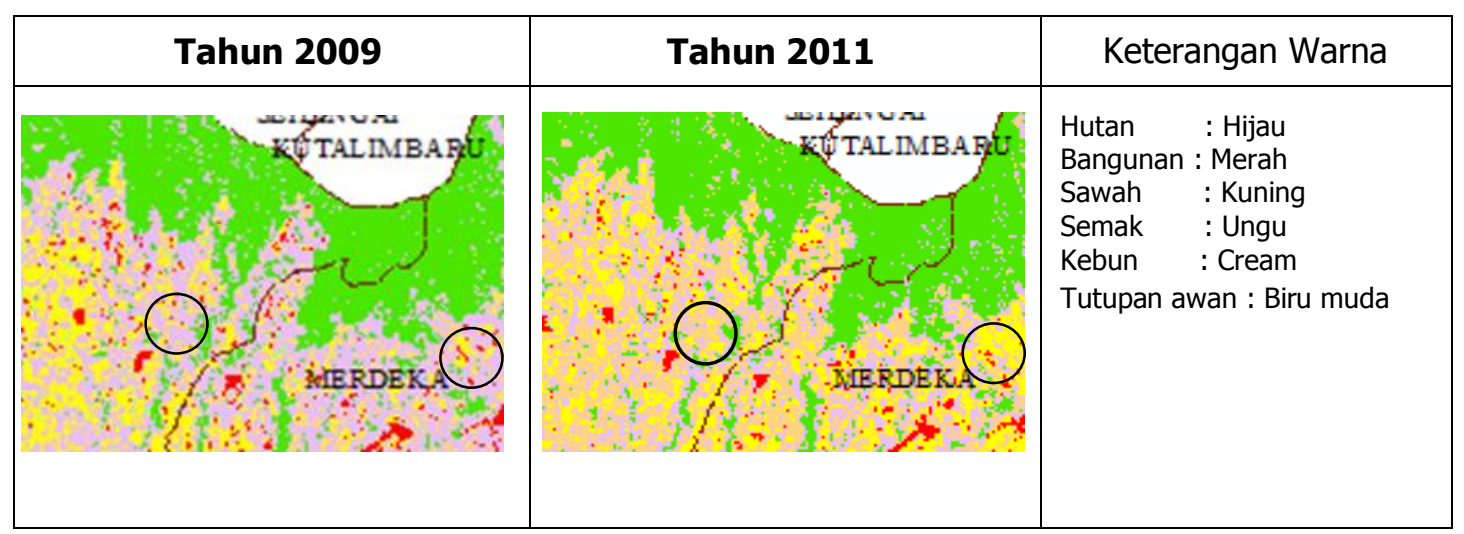

Gambar 7. Contoh Perubahan Tutupan Lahan Semak Menjadi Kebun dan Sawah

Gambar 7 menunjukkan contoh perubahan tutupan lahan dari semak menjadi kebun di Kecamatan Naman Teran dan perubahan tutupan lahan dari semak menjadi sawah di Kecamatan Merdeka. Tutupan lahan semak yang direpresentasikan dengan piksel warna ungu pada tahun 2009, pada tahun 2011 mengalami pengurangan, berubah menjadi tutupan lahan berupa kebun (di Kecamatan Naman Teran) yang direprentasikan dengan piksel warna cream dan sawah (di Kecamatan Merdeka) yang direpresentasikan dengan piksel warna kuning.

\section{KESIMPULAN}

Tutupan lahan dari hasil klasifikasi citra Landsat 5 TM tahun 2009 merepresentasikan kondisi pra letusan dan tahun 2011 merepresentasikan kondisi pascaletusan Gunungapi Sinabung. Tutupan lahan yang diidentifikasi di Kecamatan Payung, Naman Teran, Tiganderket, Merdeka, dan Simpang Empat ini terdiri dari 5 (lima) jenis tutupan lahan, yaitu hutan, bangunan, kebun, semak, dan sawah. Perubahan tutupan lahan tahun 2009-2011 yang teridentifikasi adalah hutan berkurang 1,6\%, bangunan bertambah $0,2 \%$, kebun bertambah $9,0 \%$, semak berkurang $6,8 \%$, dan sawah berkurang $0,2 \%$. Penelitian selanjutnya disarankan untuk menggunakan citra terbaru yang dapat merepresentasikan tutupan lahan saat ini dan mengambil sampel dengan cek langsung ke lapangan untuk penentuan klasifikasi tutupan yang lebih tepat, hal ini dikarenakan Gunungapi Sinabung hingga saat ini masih mengalami erupsi. Selain itu disarankan juga untuk menggunakan data citra yang memiliki resolusi lebih baik dan menggunakan metode klasifikasi yang lain, sehingga dapat diperoleh adanya peningkatan nilai uji akurasi.

\section{DAFTAR PUSTAKA}

BNPB. (2013a). Info Bencana - Informasi Kebencanaan Bulanan Teraktual. Edisi November 2013. Dipetik pada tanggal 7 Juni 2017 dari: https://bnpb.go.id/uploads/migration/pubs/ 588.pdf.

BNPB. (2013b). Riwayat Letusan Sinabung. Majalah Gema BNPB Volume IV No.3 Tahun 2013. Dipetik pada tanggal 7 Juni 2017 dari: https://bnpb.go.id/uploads/migration/pubs/589.pdf.

BNPB. (2017). Definisi dan Jenis Bencana. Dipetik pada tanggal 7 Juni 2017 dari: https://bnpb.go.id/home/definisi 
Danoedoro, P. (2012). Pengantar Penginderaan Jauh Digital. Yogyakarta: ANDI Yogyakarta Khomarudin, M.R., Wiweka, \& Sofan, P. (2014). Pemanfaatan Penginderaan Jauh Untuk Mitigasi Bencana di Indonesia. Lembaga Penerbangan dan Antariksa Nasional (LAPAN). Jakarta.

Pandia, S.L., Rachmawati, R. , dan Mei, E.T.W. (2016). Relokasi Permukiman Desa Suka Meriah Akibat Kejadian Erupsi Gunung Api Sinabung Kabupaten Karo. Jurnal Perencanaan Wilayah dan Kota Vol.27 No.2. Dipetik pada tanggal 7 Juni 2017 dari: http://journals.itb.ac.id/index.php/jpwk/article/view/1954/1259

Peraturan Kepala Badan Nasional Penanggulangan Bencana Nomor 2 Tahun 2012 tentang Pedoman Umum Pengkajian Risiko Bencana.

Purwadhi, H.S. (2001). Interpretasi Citra Digital. Penerbit Gramedia, Jakarta.

PVMBG. (2014). Peta Kawasan Rawan Bencana Gunungapi Sinabung. PVMBG, Bandung.

Rahayu, Ariyanto, D.P., Komariah, Hartati, S., Syamsiah, J., \& Dewi, W.S. (2014). Dampak Erupsi Gunung Merapi Terhadap Lahan dan Upaya-Upaya Pemulihannya. Caraka Tani Jurnal IImu Pertanian Vol. XXIX No. 1 Maret 2014. Dipetik pada tanggal 7 Juni 2017 dari: https://jurnal.uns.ac.id/ carakatani/article/view/13320.

Rwanga, S.S. dan Ndambuki, J.M. (2017). Accuracy Assessment of Land Use/Land Cover Classification Using Remote Sensing and GIS. International Journal of Geosciences, 2017, 8, 611-622. Dipetik pada tanggal 3 Agustus 2018 dari: https://file.scirp.org/ pdf/IJG_2017050414335934.pdf.

Sarkar, A. (2018). Accuracy Assessment and Analysis of Land Use Land Cover Change Using Geoinformatics Technique in Raniganj Coalfield Area, India. International Journal of Environmental Sciences \& Natural Resources Volume 11 Issue 1 - May 2018. Dipetik pada tanggal 3 Agustus 2018 dari: https://juniperpublishers.com/ijesnr/pdf/IJESNR. MS.ID.555805.pdf

Sofan, P. dan Yulianto, F. (2014). Analisis Resiko Gunung Api Merapi Berdasarkan Data Penginderaan Jauh dan Sistem Informasi Geografis. Lembaga Penerbangan dan Antariksa Nasional (LAPAN). Jakarta.

Tjandra, K. (2015). Mengenal Gunung Api, Bencana dan Manfaat Hasil Letusannya. Gadjah Mada University Press. Yogyakarta.

USGS. (2016). Landsat 8 (L8) Data Users Handbook. Dipetik pada tanggal 3 Agustus 2018 dari: https://www.usgs.gov/land-resources/nli/landsat/landsat-8-data-users-handbook. 